\title{
Análisis macroeconómico de los efectos de la liberalización financiera y comercial sobre el crecimiento económico de México, 1988-2011
}

\author{
Francisco Martínez, ${ }^{*}$ Luis Quintana** y Rafael Valencia***
}

\author{
Perfiles Latinoamericanos | Artículo \\ vol. 23 | núm. 45 | 2015 \\ pp. $79-104$
}

\section{Resumen}

Este artículo analiza cuáles han sido los principales obstáculos para el crecimiento económico de México durante los últimos veinticinco ańos, con particular énfasis en el periodo posterior a la entrada en vigor del Tratado de Libre Comercio de América del Norte (TLCAN). Si bien la política económica mexicana desde 1982 se ha guiado por una serie de suposiciones y disposiciones conocidas como el Consenso de Washington, estas políticas en lugar de estimular un mayor dinamismo de la economía mexicana han acentuado sus problemas estructurales y reducido el potencial de crecimiento del país. También se analiza cómo las políticas fiscal, monetaria, cambiaria y de libre comercio han obstaculizado el crecimiento económico.

\begin{abstract}
This article analyzes the main obstacles to economic growth in Mexico during the past twenty five years, with a focus on the period after the passage of the North American Free Trade Agreement (NAFTA). Although Mexican economic policy since 1982 has been guided by a set of assumptions and prescription known as the Washington Consensus, these economic policies rather than spurring faster economic growth have accentuated the structural problems of the Mexican economy and have reduced Mexico's growth potential. The article also analyzes how fiscal, monetary, exchange rate and free trade policies have hampered economic growth.
\end{abstract}

Palabras claves: liberalización comercial y financiera, cambio del patrón de especialización, bajo crecimiento económico.

Keywords: trade and financial liberalization, changing of specialization pattern, low economic growth.

* Candidato a Doctor en Economía por la New School for Social Research.

** Profesor Titular en Métodos Matemáticos y Estadísticos Aplicados a la Economía del Programa de Investigación de la Facultad de Estudios Superiores Acatlán de la UnAm; profesor y tutor en el Programa de Posgrado en Economía de la misma universidad.

*** Licenciado en Economía. Asistente de Investigador en el Instituto de Investigaciones Económicas de la UNAM. 


\section{Introducción ${ }^{1}$}

\section{E}

propósito de este trabajo es analizar cuáles han sido los principales obstáculos para el crecimiento económico de México en los últimos veinticinco ańos, particularmente en los años posteriores a la entrada en vigor del Tratado de Libre Comercio de América del Norte (TLCAN) en 1994. Nuestro análisis trata en específico de dos ejes de política macroeconómica clave para dicho crecimiento económico: la política financiera y la apertura comercial. La liberalización financiera se inicia en 1989, se profundiza en 1993 y se mantiene hasta la actualidad. De forma casi simultánea, la liberalización comercial se comienza en 1986, se generaliza a casi todos los sectores de la economía en 1994 y se mantiene de igual forma hasta el día de hoy.

Gráfica 1. Crecimiento económico en países seleccionados de América Latina, 1980-2011

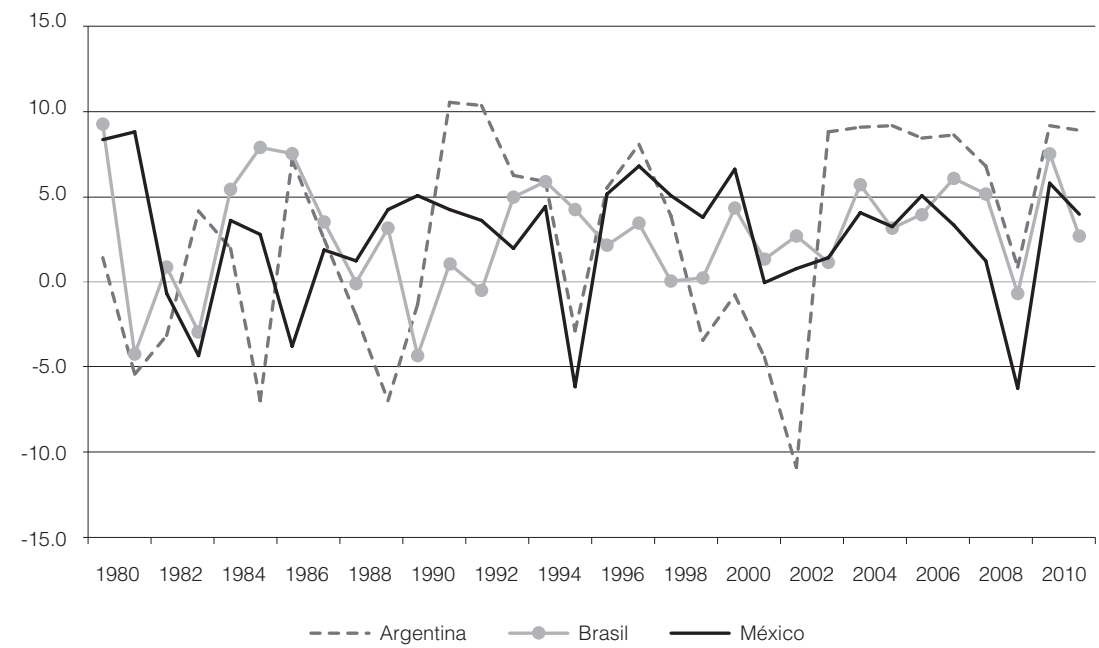

Fuente: Elaboración a partir de datos de UNCTADstat.

El análisis de la política financiera y de la apertura comercial es indispensable, ya que si bien la economía mexicana adoptó desde 1982 las directrices

1 Los autores agradecen los comentarios y sugerencias de dos dictaminadores anónimos. Algún posible error u omisión serían totalmente nuestros. 
emanadas del Consenso de Washington - las cuales le han permitido tener tasas de crecimiento que en promedio han sido bajas, pero muy similares a la de otros países de América Latina—, estas políticas (la financiera y la comercial) han acentuado sus problemas estructurales y han reducido su potencial de crecimiento, sobre todo y visiblemente desde 2003, año en que la economía mexicana empezó a mostrar un rezago considerable respecto al crecimiento de las otras dos grandes economías de América Latina (gráfica 1).

El presente trabajo se divide en seis secciones. Después de esta introducción, se hace un análisis por separado de las liberalizaciones financiera y comercial; así, las secciones segunda y tercera analizan los impactos que han tenido la liberalización financiera a ultranza sobre las finanzas públicas, las variables monetarias y el crecimiento económico. Respecto al comercio internacional de México, las secciones cuarta y quinta analizan los efectos económicos que han generado la liberalización comercial en el marco del TLCAN y el cambio del patrón de especialización internacional de la economía mexicana, respectivamente. En la última sección se exponen algunas conclusiones y propuestas de política económica.

\section{Liberalización financiera y sus repercusiones en las finanzas públicas de México, 1988-2011}

La estrategia macroeconómica aplicada durante el periodo 1982-1987 tuvo como objetivos prioritarios los equilibrios en las cuentas externas y en el presupuesto gubernamental, los cuales se buscaron básicamente a través de la contracción de la demanda interna agregada, el ajuste de los precios relativos (devaluaciones) y la reducción de los salarios reales; los resultados fueron un proceso inflacionario-devaluatorio y una contracción económica severa (Martínez, 2003). Para el periodo 1988-2011, la estrategia macroeconómica dejó de asumir como prioridad el equilibrio en el sector externo (pero mantuvo los objetivos de equilibrio presupuestal y la restricción salarial) con el fin de estabilizar los precios y acercar lo más rápido posible la tasa de inflación general de México a la de su principal socio comercial, los Estados Unidos (Calva, 2012).

Sin embargo, ante la falta de condiciones productivas y financieras internas para reducir la inflación durante los años ochenta, el gobierno se dio a la tarea de desmantelar la estructura arancelaria y de permisos previos de importaciones, primero en el marco del Acuerdo General sobre Aranceles y Comercio (GATT, por su siglas en inglés) en 1986 y posteriormente con el TLCAN, 19931994. Como resultado de la apertura comercial, se obtuvo un creciente flujo de importaciones baratas y el precio de los productos internos pasaron en gran 
medida a estar determinados por el de las importaciones, ya que la apreciación del tipo de cambio desde finales de los ochenta (este punto se verá más adelante) tendió a abaratar los precios de los productos importados y desfavoreció el de los internos. Por lo tanto, si bien estos acuerdos comerciales han contribuido a reducir la inflación nacional debido a las importaciones baratas (gráficas 2.A y 2.B), también han contribuido a crear abultados déficits de cuenta corriente que se financian con entrada creciente de capitales, situación que, como veremos más adelante, ha incrementado la fragilidad financiera, cambiaria y fiscal del país.

Gráficas 2.A y 2.B. Inflación y tasa de interés a tres meses (Cetes),

A) $1982-1988$ у B) $1989-2011$
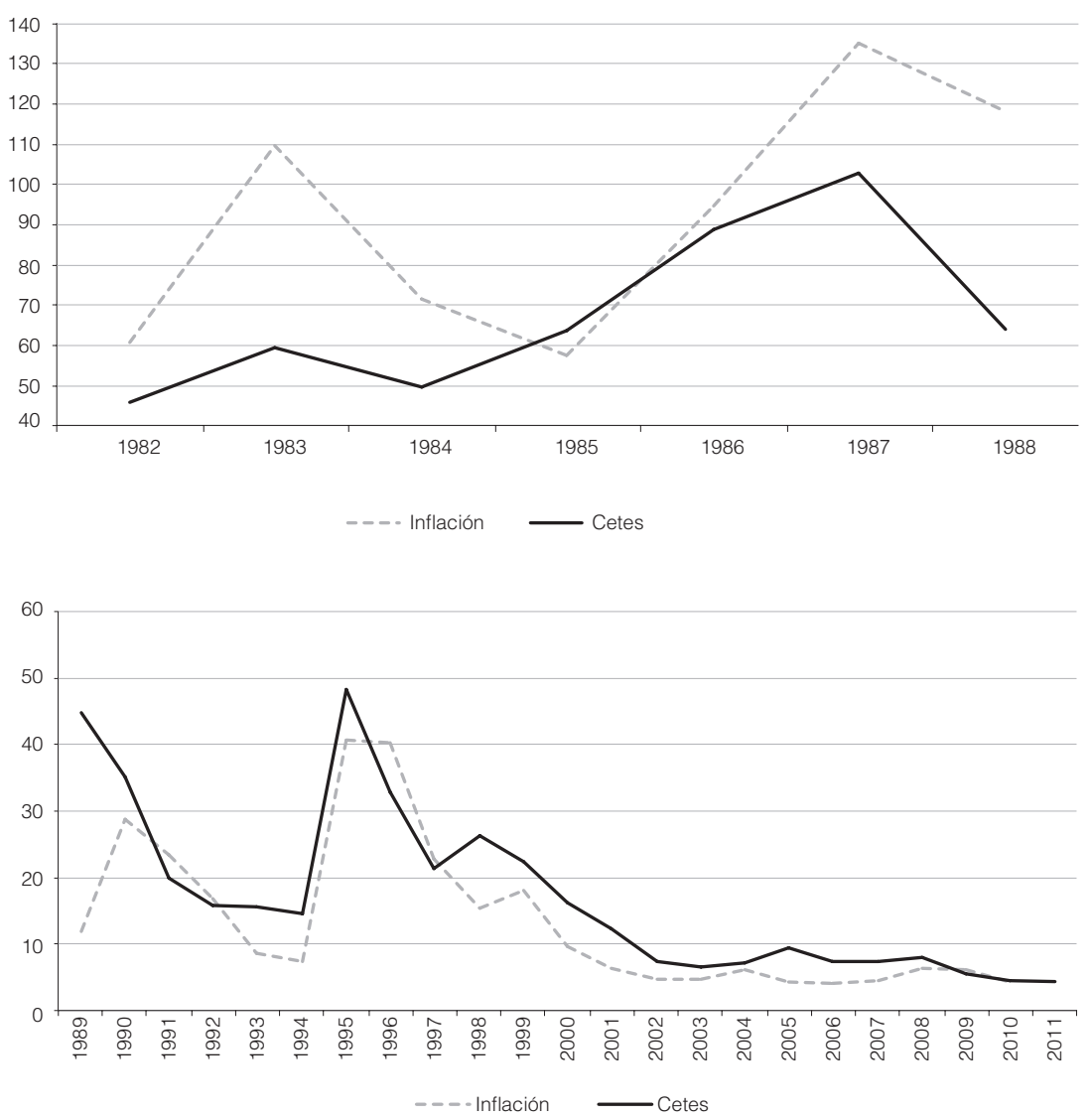

Fuente: Elaboración propia a partir de datos del Banco de México. 
De esta forma, con el propósito de atraer los capitales externos, el gobierno mexicano implementó desde 1990 la desregulación casi total del sistema financiero mexicano, con lo cual se planeaba que una mayor parte de la gran liquidez existente en el sistema financiero internacional se dirigiría al país y financiaría así el proceso de estabilización monetaria-cambiaria. Fue así que se eliminaron las restricciones a la movilidad de capitales a través de la apertura de la cuenta de capitales y se profundizó el proceso de privatización de empresas (en 1982 existían 1155 empresas del Estado, para 1986 este número se redujo a 697, en 1987 a 437 y para 1993 sólo quedaban 199 empresas estatales). Se favoreció además el desarrollo del mercado de capitales con una mayor diversidad y expansión de títulos de deuda del gobierno (Cetes, Ajustabonos, Bondes, Pagafes, Petrobonos y Unibonos).

Bajo este esquema financiero-monetario-cambiario, para mantener y atraer más capitales externos, el gobierno mexicano, de manera recurrente y desde finales de los ochenta, ha tenido que conservar amplios márgenes (spread) entre la tasa de interés de referencia de México (Cetes) y la de Estados Unidos (Treasury Bills), además de que ha ampliado otras áreas de inversión y de valorización del capital financiero en virtud de los siguientes pasos (Martínez, 2003):

- El establecimiento "oficial" de un tipo de cambio semifijo (crawiling peg) desde diciembre de 1987 hasta diciembre de 1994, con el fin de abaratar el dólar y los productos importados, y así contribuir a la reducción de la inflación.

- La liberalización del crédito y de las tasas de interés bancarias en 1989 (activas y pasivas). Esto permitió incrementar el poder oligopólico del sector bancario, ya que le facilitó la obtención de altos márgenes financieros al mantener un diferencial amplio entre la tasa de interés por préstamos y depósitos bancarios (spread) (Martínez, 2005).

- La supresión de los encajes legales (o depósitos obligatorios de los bancos comerciales en el banco central, que sólo quedó en un coeficiente de liquidez de 30\%, y el cual se abandonó totalmente en 1991).

- La apertura externa del sector financiero (mercado de valores) en sus dos vertientes: tanto para la inversión de extranjeros en el mercado bursátil y de renta fija (Cetes), como la inversión de mexicanos en el exterior, principalmente mediante la banca privada.

- La reprivatización de los bancos en 1990, con lo cual se buscaba su modernización y recapitalización para afrontar así la competencia por los recursos y márgenes financieros, ya que también se incrementó el número de intermediarios bancarios y no bancarios (casas de cambio, compañías de factoraje, aseguradoras, etcétera). 
- Además, primero en 1989 y después en 1993, se flexibilizó la ley de inversión extranjera, con lo cual se amplió la gama de oportunidades en sectores antes prioritarios del Estado.

- "La eliminación del déficit fiscal, a través de la perseverante reducción de la inversión pública, de la aceleración de la privatización de las empresas paraestatales, y del persistente achicamiento de la inversión pública y del gasto promocional del desarrollo económico" (Calva, 2007: 25-26).

Los resultados de dicho esquema de financiamiento basado en capitales externos (sobre todo de corto plazo) terminaron por mostrar su inoperancia y en diciembre de 1994 los sistemas financiero y bancario se colapsaron debido principalmente a: 1) el sobreendeudamiento de la economía, tanto en moneda nacional como en extranjera (los pasivos externos saltaron de 125002 millones de dólares en 1988 a 270196.9 millones de dólares en 1994); 2) el déficit comercial y de cuenta corriente generados por la acelerada apertura comercial (el déficit de cuenta corriente alcanzó el 7\% del producto interno bruto (PIB) en 1994), y 3) por la utilización del tipo de cambio como ancla de los precios (gráfica 6). Finalmente, el agotamiento de las divisas propiciado por la fuga de capitales y por el déficit de cuenta corriente condujeron a la maxidevaluación del tipo de cambio en diciembre de 1994, que alcanzó casi 100\% en tan sólo tres meses. La respuesta macroeconómica por parte del gobierno a esta crisis financiero-bancaria fue muy similar a la implementada en el periodo 19821987, es decir, contracción del gasto e inversión pública, alza de precios y tarifas del sector público, nuevas privatizaciones, restricción monetaria y restricción salarial (Calva, 2007). Aunque también se favoreció la subvaluación cambiaria por un corto tiempo, 1995-1996, para después pasar a un régimen de flotación controlada o sucia en 1997-2011 (Martínez, 2005).

Sin embargo, debido a que se mantuvo el objetivo de reducir de nuevo la inflación a niveles de un dígito (Programa Nacional de Financiamiento del Desarrollo, 1997), el gobierno favoreció rápidamente la sobrevaluación de la moneda, algo necesario tanto para reducir la tasa de inflación como para garantizar la rentabilidad de los activos financieros (ubicados en el mercado de dinero y en el de capitales) y de esta forma seguir atrayendo capitales externos para así financiar la liberalización económica-financiera.

Ahora bien, dado que el gobierno mexicano decidió continuar con la liberalización comercial y financiera a ultranza después de la crisis financierobancaria de 1994-1995, ha tenido que contraer la demanda agregada interna con el fin de evitar presiones de demanda sobre los precios internos y el nivel de inflación. Es decir, el gobierno mexicano ha optado por contraer la demanda agregada interna a través de dos vías: a) mediante la reducción de su gasto 
público con el propósito explícito de mantener un balance económico cercano a cero (cuadro 1), y b) a través de la reducción de los ingresos reales (salarios mínimos y medios) y de una política de flexibilización del mercado laboral (Puyana, y Romero, 2009).

En efecto, el temor a la inflación ha llevado al predominio de políticas contraccionistas de la demanda, debido a que el enfoque económico convencional que predomina en la formulación de la política económica considera que la inflación es un problema monetario. Esto dio lugar a que se le retirara al gobierno el manejo soberano de la política monetaria y se diera autonomía al banco central en abril de 1994, con lo que el gobierno perdió el control de la moneda y del financiamiento, y se vio obligado a trabajar con disciplina fiscal, por lo que se ha reducido el tamaño y participación del Estado en la actividad económica y se ha ampliado la del sector privado. De esta forma, tenemos que el gobierno deja de invertir en sectores estratégicos, lo cual amplía los espacios a la inversión privada, atrae capitales externos, aumenta la oferta de divisas y todos estos factores contribuyen finalmente a evitar que el tipo de cambio sea flexible en torno a los precios (Huerta, 2011).

Cuadro 1. Finanzas públicas (\% del PIB, en promedios simples)

\begin{tabular}{ccccccc}
\hline & $1988-1994$ & $1995-2000$ & $2001-2003$ & $2004-2006$ & $2007-2009$ & 2010-2011 \\
\hline Balance económico & -1.3 & -0.6 & -0.9 & -0.1 & -0.8 & -2.6 \\
\hline Gasto público & 25.5 & 19.4 & 21.0 & 21.3 & 23.8 & 25.4 \\
Gasto de capital & 3.3 & 2.7 & 2.7 & 3.2 & 4.3 & 5.0 \\
Gasto en intereses totales & 7.2 & 3.3 & 2.7 & 2.4 & 2.1 & 1.9 \\
\hline Ingresos públicos & 24.4 & 18.8 & 20.2 & 21.2 & 23.0 & 22.7 \\
\hline Ingresos tributarios & 9.5 & 7.6 & 8.9 & 8.6 & 9.5 & 10.0 \\
Ingresos petroleros & 6.8 & 6.1 & 6.3 & 7.9 & 7.9 & 7.6 \\
\hline
\end{tabular}

Nota: Cabe señalar que en este balance económico no se presenta la deuda total del gobierno federal, es decir, no se contabiliza la deuda generada por los pasivos netos del Fobaproa-IPAB contraídos para rescatar a los bancos, ni los PIDIREGAS que corresponden a deuda contraída con el sector privado por concepto de proyectos de inversión y los pasivos del rescate carretero.

Fuente: Elaboración de los autores a partir de los datos estadísticos de Banco de México, Finanzas públicas, y SHCP, EStadísticas de finanzas públicas.

Más aún, el gobierno mexicano no incrementa su gasto público (en particular en crisis económicas), ${ }^{2}$ no sólo para evitar presiones sobre precios y sobre

2 A este respecto, nos dice Calva (2007: 17) "que la mutilación ortodoxa de la política fiscal ha quedado amarrada con la Ley Federal de Presupuesto y Responsabilidad Hacendaria, decretada en marzo de 2006, la cual convierte en mandato de ley la política fiscal pro-cíclica, es decir, el recorte del gasto público cuando caen los ingresos fiscales". 
la demanda agregada, lo cual podría incrementar la demanda por mayores importaciones y divisas - e incrementar así las presiones sobre el tipo de cambio y por ello sobre la inflación-, debido al alto traspaso que existe del tipo de cambio a los precios. El gobierno también deja de incrementar su gasto público porque ha prorrogado por bastante tiempo una reforma fiscal integral capaz de incrementar los ingresos tributarios.

En efecto, el gasto público ha pasado a depender en forma importante de los ingresos no tributarios, es decir, de los recursos petroleros. Así, de cada peso que se recauda, en promedio 35 centavos provienen de los ingresos petroleros (Martínez, y Herrera, 2006), lo cual ha permitido al gobierno relajar su gasto sólo en los periodos de altos precios del petróleo, 2004-2006 y 2010-2011 (cuadro 1). Sin embargo, serias distorsiones sobre el aparato productivo se originan en el actual sistema tributario mexicano: por un lado, el bajo cobro de impuestos, tanto a hogares como a empresas, tiende a incrementar el ingreso disponible y con ello la demanda agregada, lo cual, dada la creciente desarticulación de las cadenas productivas, en especial después de la firma del TLCAN (este punto se verá más adelante), conduce a una mayor apreciación del tipo de cambio (por el incremento en la demanda de divisas), y, con esto, a una distorsión más grande del sistema productivo interno debido a que crece la demanda de importaciones. Por otro lado, este esquema se ve reforzado cuando aumenta el gasto público como una derivación de un mayor ingreso petrolero (Puyana, y Romero, 2009).

Por lo tanto, al no afrontar una reforma tributaria basada en impuestos progresivos sobre el ingreso, el gobierno favorece principalmente a los grandes monopolios y a la evasión fiscal, y limita así la capacidad de recaudación tributaria y de gasto público para el crecimiento económico. Al respecto cabe señalar que la débil recaudación tributaria por parte del gobierno mexicano no sólo se debe a la evasión fiscal y a la creciente economía informal (reducida base fiscal), sino también a las bajas tasas de tributación (al ingreso y al consumo) respecto a otros países de la OCDE (OCDE, 2012). Sin embargo, lo paradójico de este sistema tributario es que, muy por el contrario a lo que sugiere la teoría económica basada en la curva de Laffer, esta baja carga tributaria no se ha traducido en mayor acumulación de capital por parte del sector privado (gráfica 3).

En efecto, como se observa en la gráfica 3, si bien la formación bruta de capital fijo total (ввкFт) tuvo una considerable recuperación desde mediados de los años noventa, en términos reales este indicador aún no ha alcanzado los niveles que tuvo en los inicios de los ochenta, cuando sobrepasó el 25\% del PIB (Puyana, y Romero, 2009). Al respecto, una posible explicación del estancamiento de la FBKFT (y de la FBKFTPrivada) durante los últimos veinte años tal vez radique en la fuerte caída de la formación bruta de capital público 
(ғвкPúblico), lo cual muy probablemente también ha contribuido a la reducción y estrechez del mercado interno, y a un menor nivel de ventas y de menores ganancias, todo lo cual ha generado menores expectativas de ganancia y de retorno de las inversiones, y ha creado así un círculo recesivo de baja inversión y lento crecimiento económico.

Gráfica 3. Formación bruta de capital fijo

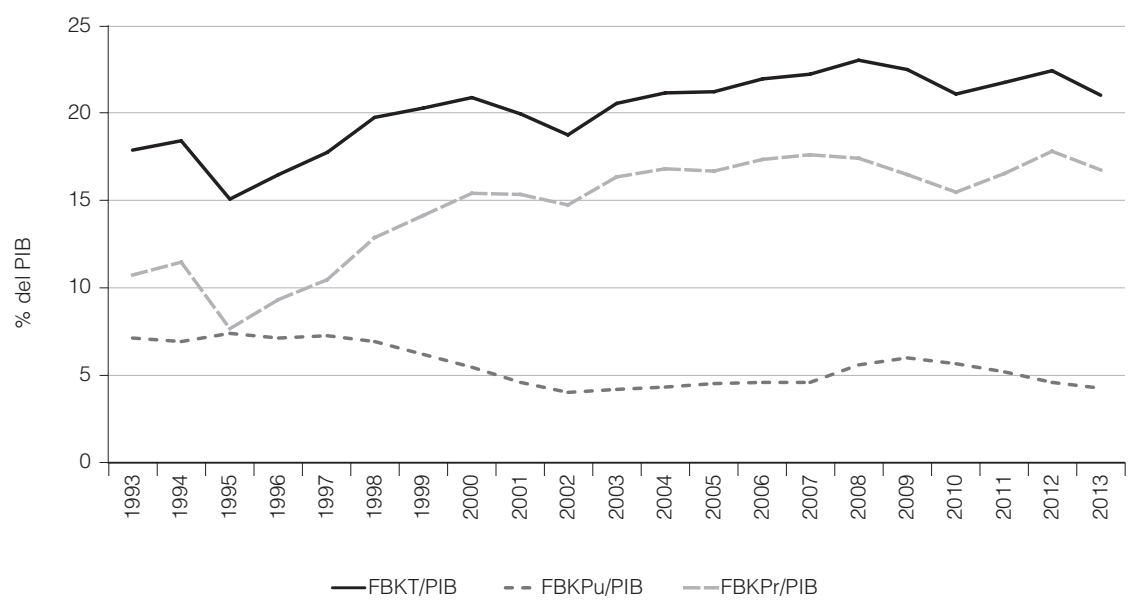

Fuente: Elaboración propia a partir de datos del INEGI: BIE.

\section{El tipo de cambio como mecanismo antiinflacionario, entrada de capitales y presiones sobre las finanzas públicas}

Oficialmente, desde diciembre de 1994 el Banco de México abandonó el régimen de tipo de cambio semifijo (crawiling peg) e inició la instrumentación de un régimen cambiario de libre flotación o flexible (Banco de México, 1999), en el que el banco central no interviene de ninguna forma (e.g., comprando o vendiendo deliberadamente divisas internacionales), para mantener un nivel "objetivo" de tipo de cambio. Una descripción simplificada de ambos esquemas cambiarios se puede representar con la siguiente ecuación:

$$
\Delta R=B P=T C+C C
$$


Esta ecuación establece que el saldo global de la balanza de pagos (BP) es igual a la suma del saldo de las transacciones corrientes (TC) y la entrada líquida de capitales en una economía (CC). Así, el saldo global de la balanza de pagos es igual a la variación de las reservas internacionales $(\Delta R)$, la cual, en un esquema de tipo de cambio fijo, varía pasivamente para compensar cualquier desequilibrio entre oferta y demanda de divisas (asociado a los resultados de la cuenta corriente y de capitales). Por el contrario, en un régimen de tipo de cambio flexible puro, el banco central no usa las reservas internacionales para intervenir en el mercado de cambios, de manera que el resultado global de la balanza de pagos (igual a la variación de reservas) es igual a cero.

En la práctica, la plena aplicación de un tipo de cambio flotante en países en desarrollo y emergentes como México es sumamente complicado, ya que factor es el principal transmisor de la inflación vía costo y nivel de las importaciones, es decir, existe una elevada dependencia tecnológica que se manifiesta en el alto nivel de insumos importados, tanto para la producción de bienes domésticos como para la producción de exportación de empresas nacionales y transnacionales. Por lo tanto, debido a estas características estructurales, los bancos centrales de los países emergentes intervienen con incrementos en las tasas de interés y con intervenciones en el mercado cambiario, para evitar que la volatilidad y depreciaciones del tipo de cambio se traduzcan en incrementos considerables de precios (Kregel, 1999; Toporowski, 2005; Mántey, 2010).

En el caso particular de México, diversas investigaciones (Ball, y Reyes, 2004; Mántey, 2010; López, 2012) señalan que para asegurar el cumplimento de las metas de inflación, el Banco de México opera la política monetaria utilizando el tipo de cambio y la tasa de interés de forma independiente. Es decir, mediante las operaciones de esterilización en el mercado de cambios, el banco central ancla el tipo de cambio; mientras que el manejo de la tasa de interés está determinado por las variaciones de las tasas de interés externas. A continuación se presenta una descripción de la forma en que funcionan ambos mecanismos:

- La reforma financiera de inicio de los noventa redujo de forma drástica el margen de acción de la autoridad monetaria para regular el nivel de liquidez de la economía (debido a la desaparición de los encajes legales). Por lo tanto, desde mediados de 1995, el Banco de México ha tenido que mantener una tendencia negativa del crédito interno neto hacia el sector público (lo ha contraído para evitar la expansión de la base monetaria), tendencia que coincide con un incremento en la acumulación de reservas internacionales (gráfica 4). Ello es un indicio de que el Banco de México recurre frecuentemente a las operaciones de esterilización en el mercado cambiario, al mismo tiempo que realiza operaciones tradicionales de merca- 
do abierto (López, 2012: 179). Adicionalmente, de 1997 a 2001, el Banco de México mantuvo un esquema de compra y otro de venta de divisas internacionales a intermediarios financieros, con el objetivo explícito de reducir la volatilidad del tipo de cambio (Banco de México, 2007).

- Respecto al manejo de las tasas de interés, el Banco de México le ha asignado un papel residual en el logro de la estabilidad del tipo de cambio. Es decir, según algunas investigaciones empíricas, las modificaciones en el tipo de cambio son las que anteceden a los movimientos de la tasa de interés y no a la inversa, como lo sostiene la teoría monetaria convencional (Ball, y Reyes, 2004; Mántey, y Levy, 2007; Mántey, 2009). Por lo tanto, que la causalidad se presente de la tasa de cambio a la tasa de interés implica el pleno reconocimiento por parte del banco central de que las fluctuaciones del tipo de cambio mantienen un alto traspaso hacia los precios. De esta forma, el manejo de la tasa de interés busca principalmente mantener un margen atractivo respecto a las tasas de interés externas, y así atraer flujos de capitales externos de cartera (López, 2012: 183).

\section{Gráfica 4. Reservas internacionales y crédito interno neto}

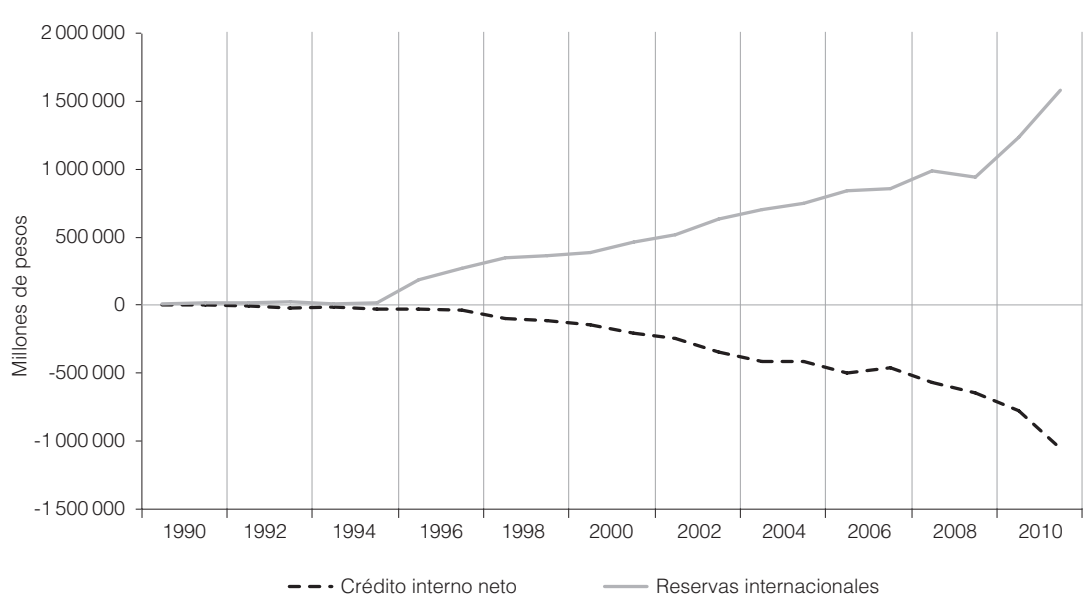

Fuente: Elaboración propia a partir de datos del Banco de México.

Sin embargo, a pesar de que el Banco de México conserva la estabilidad monetaria-cambiaria al mantener de modo permanente una política de esterilización de capitales externos, el régimen de tipo de cambio controlado genera un alto costo fiscal, ya que ante el incremento de los flujos de capitales (de 
cartera, inversión extranjera directa (IED), remesas, etc.), el Banco de México los tiene que esterilizar total o parcialmente mediante la emisión de títulos de deuda del gobierno federal, con el fin explícito de reducir el impacto monetario de los flujos de capitales sobre la base monetaria y los precios.

En este sentido, tenemos que desde finales de 1998 el Banco de México ha colocado, mediante subastas en el mercado secundario, montos importantes de Bonos de Desarrollo del Gobierno Federal (Bondes) a 28 y 91 días, con cargo al propio instituto emisor. Además, las intervenciones del Banco de México en el mercado de dinero las realiza con la emisión de Bonos de Regulación Monetaria (Brems), cuya salida inició en agosto de 2000 como un instrumento propio del Banco de México para retirar excedentes de liquidez del mercado de dinero.

Para 2010, los Brems se convirtieron en el principal instrumento de deuda emitido por el Banco de México, ya que superó más del 50\% del total de las emisiones de valores gubernamentales (López, 2012). Por lo tanto, mediante la esterilización de capitales, el Banco de México mantiene estable el tipo de cambio, y así los precios internos, pero a costa de crear un crecimiento acelerado de la deuda pública interna (gráfica 5). Esta política de esterilización de capitales acarrea serios riesgos económicos y financieros importantes debido a que el incremento de deuda no es para elevar el gasto e inversión pública y con esto el crecimiento económico, sino para acumular reservas internacionales, las cuales finalmente se invierten con una tasa de interés mucho menor en el tesoro estadounidense, lo cual genera una pérdida cuasi fiscal para el Estado mexicano derivada del diferencial de tasas de interés internas versus externas (Kregel, 1999).

Gráfica 5. Composición de la deuda pública como proporción del PIB

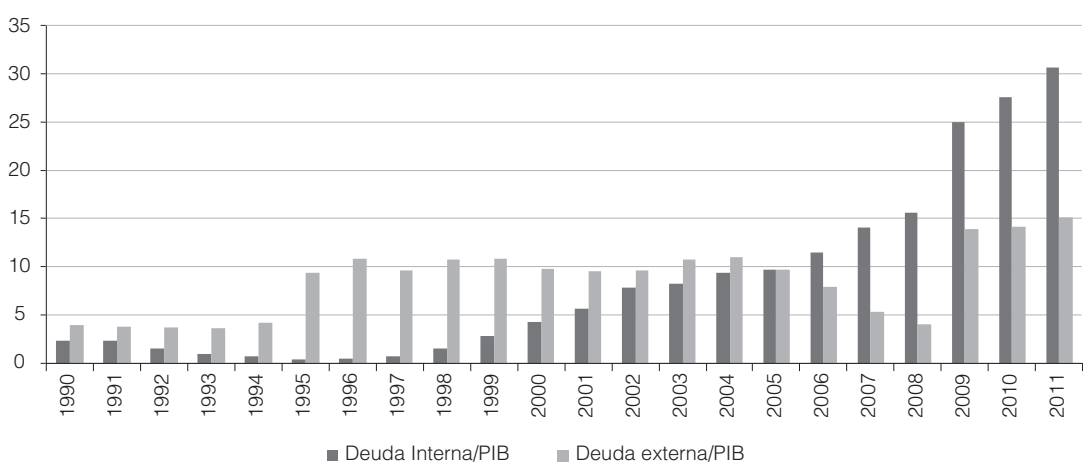

Fuente: Elaboración propia a partir de datos del Banco de México y del INEGI. 


\section{El patrón comercial de México, problemática y límites del sector externo, 1988-2011}

El cambio y orientación del proteccionismo comercial de México se inicia desde 1977, cuando se comienzan a "arancelizar" los permisos de importación para después reducirlos de manera progresiva. Así, el proceso de apertura comercial ya estaba relativamente iniciado para cuando México se incorporó al GATT en 1986, y, para 1989, esta política aperturista se acentúa al reducirse súbitamente los permisos de importación y al sobrepasar por mucho la desgravación arancelaria comprometida en el GATT.

En enero de 1994, con la entrada en vigor del TLCAN entre Canadá, Estados Unidos y México, la apertura comercial se institucionaliza y se generaliza a casi todos los sectores económicos (excepto el mercado laboral y con algunas restricciones temporales en ciertos sectores, sobre todo agrícolas). De esta forma, la economía mexicana pasó, en unos años, de un régimen comercial que mantenía un riguroso régimen de racionamiento de las importaciones (el cual ayudaba a sostener el proceso de industrialización por sustitución de importaciones y a aminorar los problemas de balanza de pagos), a un esquema de liberalización comercial acelerada y unilateral, principalmente frente a Estados Unidos (Gazol, 2009; Ros, y Moreno-Brid, 2009). ${ }^{3}$

A simple vista, para el caso de la economía mexicana, el balance económico del proceso de liberalización comercial acelerada ha tenido relativo éxito, ya que redujo de forma considerable el sesgo antiexportador y petrolizado de las exportaciones nacionales que caracterizó a la economía mexicana hacia inicios de los ochenta. Sin embargo, de acuerdo a diversas investigaciones, esta rápida transformación exigió la reestructuración industrial del aparato productivo mexicano, lo cual ha resultado en la ruptura de diversas cadenas productivas domésticas y ha atentado contra el crecimiento de largo plazo del empleo y de la economía en su totalidad (Guillén, 2005; Puyana, y Romero, 2009; Ros, y Moreno-Brid, 2009). ${ }^{4}$

3 "En general, desde el inicio de la liberalización del comercio en 1984-1985 a 1993, un año antes de que entrara en vigor el Tratado de Libre Comercio de América del Norte (TLCAN), la cobertura de la licencia de importación se redujo de $83.5 \%$ (1984) a 21.5\%. El promedio ponderado de la producción arancelaria se redujo de $23.5 \%$ (1985) a 12.5\%, y el arancel máximo se redujo de $100 \%$ (1985) a $25 \%$ (Tornell y Esquivel, 1997)" (Ros, y Moreno-Brid, 2009: 163).

4 A grandes rasgos, como se verá más adelante, en México la estrategia post TLCAN se ha sustentado en el sector exportador, ya que de las 35 mil empresas exportadoras que existen, menos de 500 llevan a cabo $70 \%$ de las exportaciones. Estas grandes empresas tienen un alto componente importado; en consecuencia no tienen efectos multiplicadores en el mercado interno y su competitividad se sostiene en bajos salarios y en un peso fuerte.

Perfiles Latinoamericanos | vol. 23, núm. 45, enero-junio de 2015 | FLACso México 
A continuación presentamos dos conjuntos de posturas acerca de los beneficios y desventajas de la integración económica de México en el marco del TLCAN.

Beneficios:

- Existe un consenso entre los defensores del tLCAN de que este tratado fue un instrumento importante detrás del crecimiento de las exportaciones y de la inversión extranjera directa (IED). Además, se reconoce que gracias a este acuerdo comercial la economía tuvo una rápida recuperación después de la crisis económica de 1995, ya que permitió a empresas locales y extranjeras (dentro y fuera de la región del TLCAN) invertir en la producción de bienes comerciales, creando así una plataforma de exportación dinámica hacia Estados Unidos. Es importante señalar que esta plataforma de exportación se benefició de forma importante con la maxidevaluación del tipo de cambio en 1995 (gráficas 6 y 7). De tal forma, tenemos que las exportaciones de bienes pasaron de 40.7 mil millones de dólares en 1990, a 166 mil millones de dólares en 2000 y a 288.4 mil millones de dólares en 2010. Para el periodo 1990-2010, estos montos reflejaron una tasa de crecimiento media anual en dólares corrientes de 9.7\%. En tanto que la IED pasó de 2.6 mil millones de dólares en 1990, a 18.1 mil millones de dólares en 2000, y a 20.7 mil millones de dólares en 2010 (Guillén, 2005; Ros, y Moreno, 2009; Banco de México).

- Con las devaluaciones de 1994-1995, hubo un cambio notable en la composición de los flujos financieros netos hacia el país. Es decir, la mayoría de los flujos que recibió México de 1990 a 1994 se componían de capitales de cartera, los cuales rápidamente huyeron del país durante la crisis financiera de 1994-1995, mientras que en este mismo periodo la IED fue relativamente pequeña. Sin embargo, durante el periodo 19952009, la IED representó la mayor parte de las entradas netas de capitales: en 1990 la relación de la IED a flujos netos totales fue de 56.9\%, en 2000 de $98 \%$ y en 2009 de $50 \%$. Además, cabe señalar que entre enero de 1999 y septiembre de 2009, las empresas con inversión estadounidense establecidas en México realizaron inversiones por 122515.8 millones de dólares, lo que representó $54 \%$ de la IED total que recibió México en ese periodo (ProMéxico, 2010).

- El auge exportador de México se ha reflejado vigorosamente en la balanza comercial bilateral México-Estados Unidos. Desde 1995, México ha mantenido un superávit comercial con su principal socio comercial, Estados Unidos, pero no con Canadá (Moreno et al., 2005; Blecker, 2005; Ros, y Moreno-Brid, 2009). En 2009, la composición de las exportaciones hacia Estados Unidos fue la siguiente: $76 \%$ lo ocuparon 
las manufacturas, $17 \%$ los combustibles y $3 \%$ los productos agrícolas (ProMéxico, 2010).

\section{Desventajas:}

- Por el contrario, la principal y más clara repercusión de la integración comercial de México con la economía de Estados Unidos es que la economía mexicana, al igual que la mayor parte de las centroamericanas, se ha vuelto más dependiente del crecimiento económico de Estados Unidos y del grado de competitividad mexicana en el mercado estadounidense. En efecto, la expansión económica estadounidense en los años noventa favoreció el crecimiento de las exportaciones mexicanas (Blecker, 2005) ya que ella absorbe alrededor del $80 \%$ de estas últimas. Sin embargo, las recesiones económicas de Estados Unidos de 2001 y 2007-2008 han provocado recesiones más profundas en la economía mexicana. De tal forma, estas desaceleraciones han contribuido de modo importante al estancamiento de la IED hacia México, a la reducción de las exportaciones mexicanas y a la pérdida de competitividad frente a la economía de China en el mercado estadounidense. Esto ha sido así, porque, desde 2006, China desplazó a México como segundo socio comercial de los Estados Unidos. En términos de dólares nominales en el periodo 2001-2011, la IED tuvo un lento crecimiento promedio anual de solo 5.6\%, y para el mismo periodo, las exportaciones de bienes tuvieron un crecimiento promedio anual en términos de dólares nominales de 7.8 por ciento.

- Otro de los efectos de esta reestructuración industrial de México con orientación hacia el sector externo es que aquélla ha tendido a concentrar la actividad productiva (sobre todo con capital extranjero) en un pequeño número de grandes firmas. Asimismo, la modernización industrial neoliberal ha parcializado regionalmente la actividad productiva, agravando los desequilibrios al excluir aún más a los estados del sur del país no conectados territorialmente con Estados Unidos (Guillén, 2005).

- El uso del tipo de cambio como ancla antiinflacionaria y como variable financiera para atraer capitales externos ha tendido también a agravar la posición comercial de México con el resto del mundo. Como se puede observar en la gráfica 6, el comportamiento y evolución del índice del tipo de cambio real ${ }^{5}$ para el periodo $1988-2011$ muestra que esta variable macroeconómica ha tenido cierta influencia sobre el comportamiento y

5 En este cálculo del índice del tipo de cambio real $\left(e^{*} P f(P d)\right.$, el incremento del índice significa una depreciación y una reducción significa apreciación del tipo de cambio real. $P f$ significa precios extranjeros y $P D$ precios domésticos. 
evolución de la balanza comercial total y, especialmente, sobre la balanza comercial no petrolera, ambas con respecto al PIB. En la gráfica 6 también podemos apreciar que con las devaluaciones de 1994-1995, ambas balanzas comerciales respondieron positivamente al nuevo nivel del tipo de cambio real. Sin embargo, el efecto favorable sobre la posición comercial del país se desvaneció rápidamente conforme el tipo de cambio real tendió a apreciarse de nueva cuenta entre 1996 y 1997 . Para el periodo 1998-2011, el índice de tipo de cambio real revela que las autoridades monetarias se han inclinado por mantener una apreciación real del tipo de cambio de alrededor de $7 \%$ promedio anual. Ello, sin duda, puede ser muy atractivo para la rentabilidad de activos financieros ubicados en el país y para las importaciones, pero no para la producción y empleo domésticos.

Gráfica 6. Balanza comercial y comercial no petrolera con relación al PIB e índice de tipo de cambio real

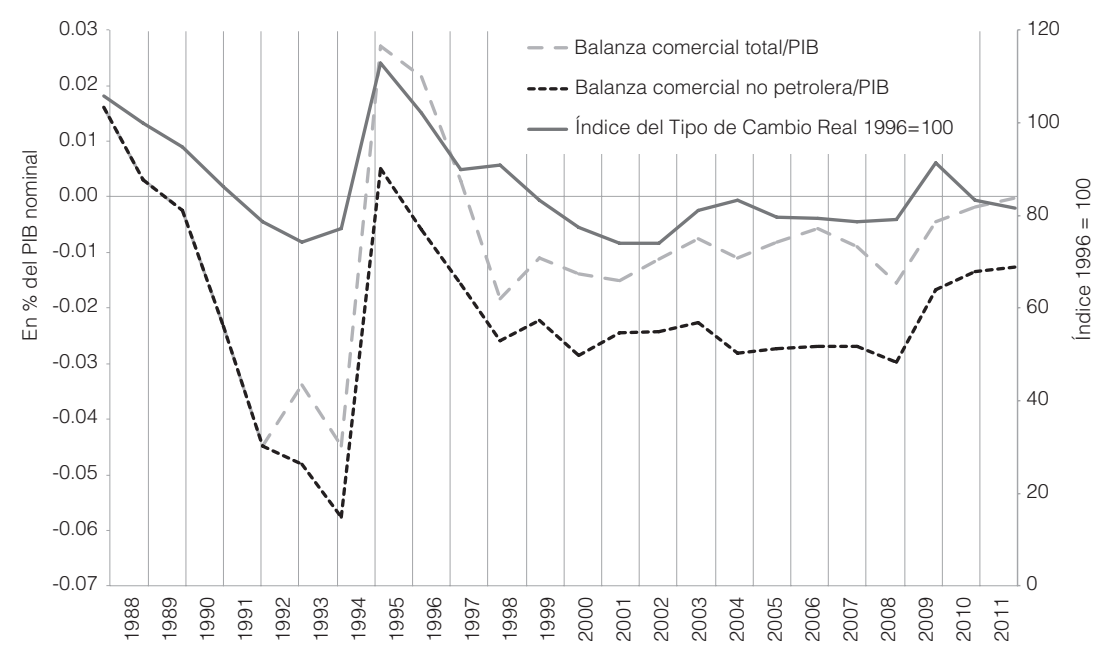

Fuente: Elaboración propia a partir de datos de Banco de México, INEGI (BIE) y World Bank (DataBank).

\section{El patrón de especialización internacional de la economía mexicana bajo el TLCAN}

Como resultado del cambio en la orientación comercial de México en medio de la crisis de la deuda externa en los años ochenta, de las constantes deprecia- 
ciones del tipo de cambio y de la caída del precio internacional del petróleo de inicios de los ochenta, la estructura productiva y comercial de México inició un lento pero constante cambio estructural en su sector externo. Esto fue así porque las exportaciones petroleras y las de bienes primarios redujeron rápida y considerablemente su participación en el total de exportaciones, mientras que las exportaciones no petroleras (básicamente manufactureras) iniciaron un dinámico crecimiento. Así, a partir de la firma y entrada en vigor del TLCAN en 1994, el desarrollo y expansión de las exportaciones se consolidan y mantienen un ritmo de crecimiento bastante importante hasta el año 2000 (gráficas 7 y 8).

En ese sentido, hacia finales de los ochenta e inicios de los noventa, la economía mexicana pasó de ser una economía tradicionalmente exportadora de petróleo crudo, de bienes primarios (café, camarones, frutas y tomates), y de algunos pocos bienes manufacturados con bajo grado de sofisticación, a una economía con crecimiento notable en sus exportaciones manufactureras con alto desarrollo tecnológico, lo cual permitió que la economía mexicana se posicionara rápidamente en los mercados mundiales de comercio de manufacturas (cuadro 2). En efecto, como se observa en el cuadro 2, la primera parte muestra el grado de participación de las exportaciones mexicanas por sectores en los mercados de la OCDE, y la segunda, el peso relativo de cada sector en el total de las exportaciones mexicanas. Las exportaciones manufactureras no basadas en recursos naturales ampliaron significativamente su participación en los mercados de la OCDE durante cada lustro en que se calculó la participación de mercado.

En cuanto a las manufacturas basadas en recursos naturales, si bien mantuvieron un crecimiento en los primeros años de los noventa, su peso relativo fue muy bajo para todo el periodo de análisis. En lo que se refiere a los recursos naturales, su participación en los mercados de la OCDE fue menos dinámica, y fueron las exportaciones agrícolas las que más alta participación mostraron respecto a las exportaciones del sector energético y de las exportaciones de textiles, minerales y metales. En relación con las exportaciones del sector energético, básicamente petróleo crudo, la disminución de la participación tanto en los mercados de la OCDE como en el total de las exportaciones mexicanas (segunda parte del cuadro 2), no se ha logrado revertir a pesar de la tendencia creciente del precio internacional del petróleo desde 2004 (Ros, y Moreno-Brid, 2009).

Como se observa en la segunda parte del cuadro 2, la estructura de exportaciones muestra claramente una tendencia hacia la especialización internacional en la producción de bienes manufacturados, donde las exportaciones no basadas en recursos naturales y con mayor componente tecnológico ${ }^{6}$ despuntan

6 Según Guillén (2005: 210), dos resultados confirman este mayor desarrollo tecnológico en las manufacturas mexicanas en los ańos noventa. En primer lugar, el resultado del Indicador de Desarrollo 
desde 1995, apuntaladas básicamente por la devaluación real del tipo de cambio de 1995 y por el crecimiento económico estadounidense. Además, cabe señalar que esta estructura de especialización internacional contrasta claramente con la del conjunto de América Latina. Es decir, si ubicamos a México y el Caribe por un lado y a América del Sur por el otro, vemos que los primeros se especializan en manufacturas no basadas en recursos naturales como es el caso de la industria automotriz, la electrónica, computadoras y la confección de prendas de vestir; mientras que los segundos se especializan en recursos naturales y manufacturas basadas en ellas (Guillén, 2005; Ros, y Moreno-Brid, 2009).

Cuadro 2. Concentración y estructura de las exportaciones mexicanas

\begin{tabular}{|c|c|c|c|c|c|}
\hline México & 1990 & 1995 & 2000 & 2005 & 2011 \\
\hline Concentración de Mercado & 1.4 & 2.6 & 4.4 & 3.8 & 4.3 \\
\hline Recursos naturales & 4.3 & 3.5 & 4.4 & 4.8 & 4.6 \\
\hline Agricultura & 2.2 & 2.7 & 3.2 & 2.9 & 3.2 \\
\hline Energía & 10.4 & 7.7 & 7.2 & 7.5 & 7.1 \\
\hline $\begin{array}{l}\text { Fibras textiles, minerales } \\
\text { y metales }\end{array}$ & 1.0 & 1.3 & 1.4 & 1.7 & 1.3 \\
\hline Manufacturas & 0.8 & 2.6 & 4.4 & 3.6 & 4.4 \\
\hline $\begin{array}{l}\text { Basados en recursos } \\
\text { naturales }\end{array}$ & 0.8 & 1.3 & 1.9 & 1.6 & 1.5 \\
\hline $\begin{array}{l}\text { No basados en recursos } \\
\text { naturales }\end{array}$ & 0.8 & 3.4 & 5.8 & 5.1 & 6.8 \\
\hline Otros & 0.2 & 0.3 & 0.1 & 0.5 & 2.3 \\
\hline Estructura de las Exportaciones & 100.0 & 100.0 & 100.0 & 100.0 & 100.0 \\
\hline Recursos naturales & 53.4 & 19.5 & 13.4 & 20.2 & 20.2 \\
\hline Agricultura & 10.9 & 7.0 & 3.8 & 4.2 & 4.7 \\
\hline Energía & 38.8 & 10.4 & 8.6 & 14.6 & 14.4 \\
\hline $\begin{array}{l}\text { Fibras textiles, minerales } \\
\text { y metales }\end{array}$ & 3.8 & 2.1 & 1.0 & 1.4 & 1.1 \\
\hline Manufacturas & 43.2 & 69.1 & 72.7 & 66.1 & 67.3 \\
\hline $\begin{array}{l}\text { Basados en recursos } \\
\text { naturales }\end{array}$ & 16.9 & 14.0 & 11.3 & 11.6 & 10.2 \\
\hline $\begin{array}{l}\text { No basados en recursos } \\
\text { naturales }\end{array}$ & 26.4 & 55.1 & 61.4 & 54.5 & 57.1 \\
\hline Otros & 0.4 & 0.3 & 0.1 & 0.4 & 2.7 \\
\hline
\end{tabular}

Fuente: Elaboración propia a partir de los datos estadísticos en línea de la OECD Database, International Trade by Commodity, disponible en: <www.oecd-ilabrary.org>, consulta del 6 de julio de 2012

Tecnológico (IDT) generado por el PNUD para evaluar el nivel de innovación y de difusión de tecnologías de un país, así como el grado de formación de las competencias humanas, señala que de sus tres niveles posibles, México forma parte del segundo grupo, el de los líderes potenciales, con un IDT de 0.389 que lo coloca en el lugar 32 de los países considerados, y supera a todos los países de América Latina. En segundo lugar, tenemos que el Índice de Especialización Tecnológica (IET) de México aumenta de 0.650 en 1985, ańo de la apertura, a 1.582 en 1998. Esta última cifra es superior a la de los países del 
Ahora bien, por un lado tenemos que las devaluaciones del tipo de cambio de 1994-1995 fueron un elemento importante detrás del crecimiento de las exportaciones totales, y manufactureras en particular, ya que a partir de 1993 las exportaciones maquiladoras dejaron de contabilizarse en la cuenta de servicios para serlo en la cuenta de bienes. Por lo tanto, si descontamos este factor, se concluye que las exportaciones manufactureras mantienen un gran crecimiento, pero menor y más realista (gráficas 7 y 8). Por otro lado, la IED proveniente de las empresas transnacionales antes y después de la firma del TLCAN con el objeto de explotar la cercanía con Estados Unidos, en especial las inversiones en la industria maquiladora, constituyó un factor adicional de importancia detrás del boom exportador de mediados de los noventa. Sin embargo, si bien la industria maquiladora ha sido un factor importante detrás del auge exportador mexicano -representa aproximadamente $40 \%$ de las exportaciones totales (gráficas 7 y 8)-, las exportaciones maquiladoras han generado importantes distorsiones en la economía mexicana (Puyana, y Romero, 2009).

Un primer acercamiento a la comprensión de estas distorsiones la podemos ver en la gráfica 7, donde se puede observar el efecto de arrastre real de las exportaciones totales mexicanas sobre el PIB en el periodo 1987-2006. Es decir, si a las exportaciones totales les descontamos el valor de las importaciones de las maquiladoras (componentes de ensamble), para así obtener el aporte neto en valor de las exportaciones totales sobre el conjunto de la economía mexicana, vemos que el dinamismo exportador no lo es tanto. Este indicador (exportaciones totales menos las importaciones de las maquiladoras como porcentaje del PIB) aumentó $9.8 \%$ entre 1987 y 2006, al pasar de 9.5 a 19.3\%, y de 1994 a 1995 el incremento más significativo es de 9.6 a 18.6\%. Además, las gráficas 7 y 8 muestran que los incrementos más notables en las exportaciones (totales, de maquila y no maquila) ocurren a raíz de las devaluaciones de la moneda en 1994-1995, y conforme el tipo de cambio se ha apreciado desde 1996, el crecimiento y la proporción del valor de las exportaciones en el pIB (especialmente las exportaciones no maquiladoras) ha dejado de incrementarse. Por último, si observamos de nueva cuenta las gráficas 7 y 8 simultáneamente, podemos ver que para el periodo 1993-2006 la diferencia entre las exportaciones e importaciones del sector maquilador fue de alrededor de $+2 \%$ del PIB, promedio anual. Por lo tanto, se confirma que, en la esfera macroeconómica, el poder de arrastre de la industria maquiladora sobre el conjunto de la economía resulta ser, en términos relativos, muy reducido.

Mercosur (0.343), a la del conjunto de América Latina (0.526), a la de China (0.534), y similar a las de República de Corea, Hong Kong, Singapur y Taiwán (1.508). 
Gráfica 7. Exportaciones totales y factor de arrastre de las exportaciones en relación al PIB, 1987-2007

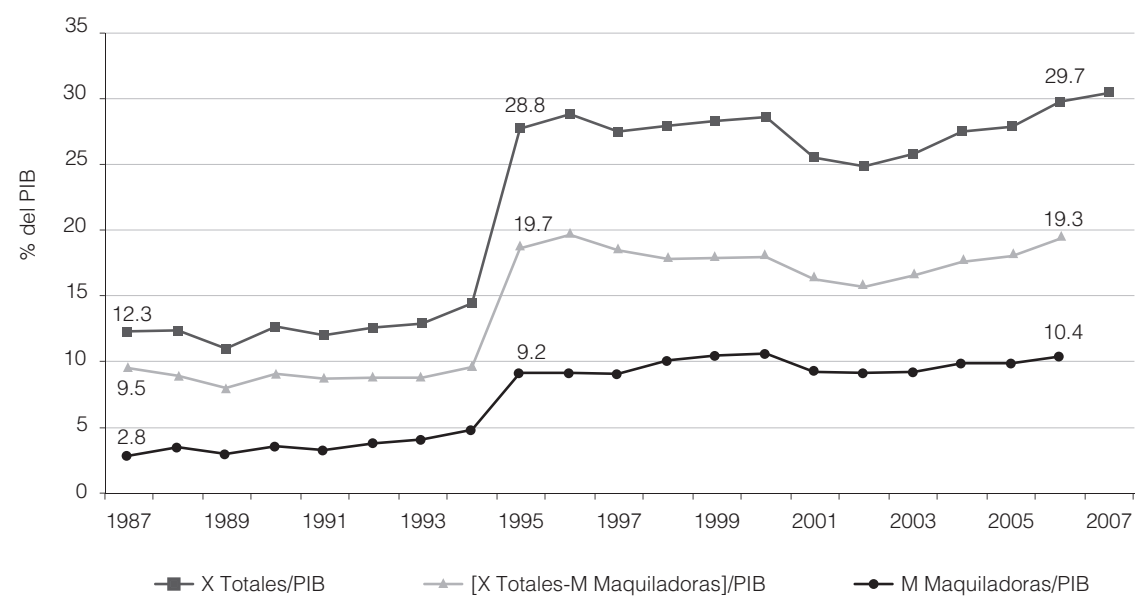

Gráfica 8. Exportaciones manufactureras con relación al PIB, 1993-2006

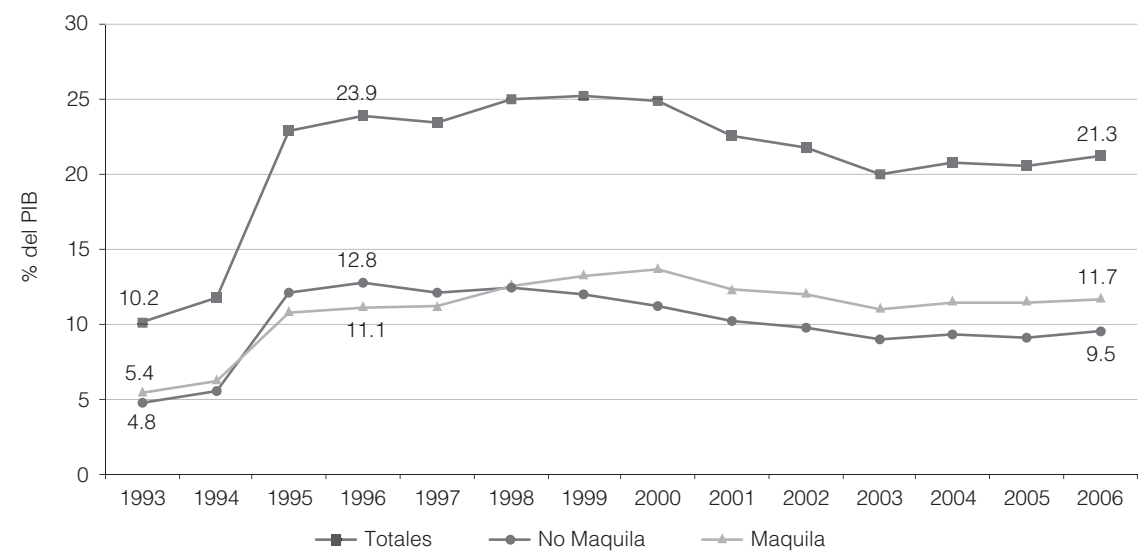

Fuente: Elaboración propia a partir de datos de Banco de México e INEGI (BIE).

Cabe añadir que el impacto del auge exportador sobre la economía doméstica también ha sido limitado, ya que por un lado las exportaciones maquiladoras (las más dinámicas) no contribuyen al fisco y, por el otro, la demanda de insumos productivos domésticos por parte del sector maquilador se ve limitada por restricciones de costos y debido al TLCAN. Es decir, por el lado mexicano la industria maquiladora no paga impuestos de importaciones de los insumos. Mientras que por el lado norteamericano (debido a "la regla de origen" del 
TLCAN que exige más del 50\% de componente regional) existe el cobro de impuestos cuando los productos no tienen ese origen. De tal forma, tenemos que no existe una vinculación directa entre el crecimiento de las exportaciones de la maquila y la del resto de la economía, así como en la generación de empleo y valor agregado totales (Guillén, 2005; Puyana, y Romero, 2009).

A este respecto, Puyana y Romero (2009) señalan que las exportaciones maquiladoras han venido reportando una caída importante en la generación de valor agregado nacional y un bajo dinamismo a nivel sectorial (principalmente en el automotriz y eléctrico-electrónico), sobre todo a partir de la entrada en vigor del TLCAN. Ello explica un estancamiento similar en la absorción de factores productivos internos y una caída importante en la productividad del sector maquilador. En efecto, de acuerdo con estos autores, la revaluación del tipo de cambio parece no afectar a las exportaciones maquiladoras, sin embargo, la revaluación reduce la absorción de factores productivos domésticos y, por ende, la incorporación de mayor valor agregado nacional. En este sentido, según los cálculos realizados por estos mismos autores, $1 \%$ de crecimiento de las exportaciones de la maquila se ve reflejado, a su vez, en un crecimiento de solo $0.007 \%$ del рів. Por lo tanto, la contribución de las exportaciones maquiladoras a la economía en su conjunto es muy baja. Finalmente, si consideramos que hasta 2006 alrededor de $85 \%$ de las exportaciones se concentraban en la maquila y en el Pitex, ${ }^{7}$ las cuales tienden a ser exportaciones intensivas en trabajo y no en capital, veremos que en realidad la economía mexicana se ha orientado a exportar productos maquilados intensivos en mano de obra, los cuales terminan generando un bajo contenido de valor agregado nacional, no solo por el bajo contenido nacional de los productos maquilados, sino también por los bajos salarios que ofrecen las empresas maquiladoras (Minian, 2008; Puyana, y Romero, 2009).

Como se puede apreciar con la información arriba señalada, este esquema de crecimiento económico conducido por la industria maquiladora favorece en mayor medida la importación de insumos o, expresado de otra forma, este esquema mantiene la vocación de sustituir trabajo nacional por importado, lo cual ha debilitado y desarticulado la industria nacional por el rompimiento de cadenas productivas domésticas, y ha llevado a un proceso de desindustrialización constante y a la creación de un déficit comercial estructural (gráfica 6). En este sentido, en la gráfica 9 se observa que la economía mexicana mantiene

7 De 1990 a 2006, el gobierno de México instrumentó el Programa de Importaciones Temporales para producir artículos de Exportación (Pitex) y el Programa de Empresas Altamente Exportadoras (Altex). Ambos tenían la función de simplificar los trámites para importar insumos de cualquier parte del mundo, sobre todo para la industria maquiladora. Además ambos programas gozaban de la excepción del pago de impuestos de importación y de los impuestos al valor agregado (IVA). 
un superávit comercial creciente con Estados Unidos; sin embargo, allí mismo también se aprecia que desde 2003 la economía mexicana ha incrementado considerablemente su saldo comercial deficitario con las principales economías de la Unión Europea y del Sudeste Asiático, pero principalmente con la economía de China, la cual no solo ha desplazado a la mexicana en el mercado norteamericano, sino también en el plano nacional, tanto en lo que se refiere a productos finales como a mayor demanda de componentes importados para la industria maquiladora mexicana (Minian, 2008).

\section{Gráfica 9. Balanza comercial de México con países seleccionados, en miles de millones} de dólares, 1993-2012

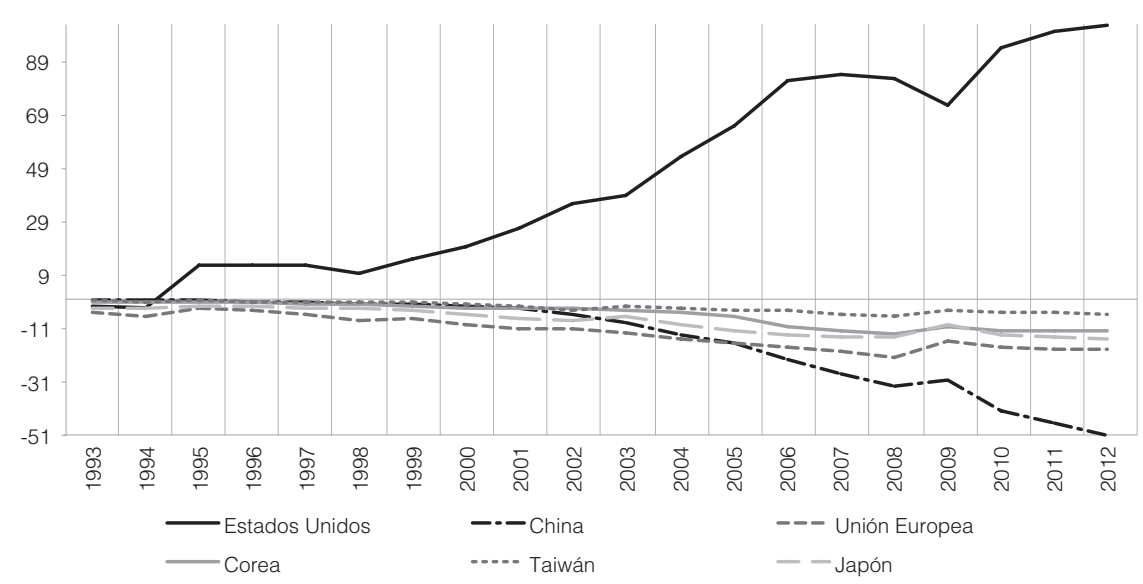

Fuente: Elaboración propia con datos de la Secretaría de Economía.

\section{Conclusiones y propuestas de política económica}

En este trabajo se ha podido apreciar que la estrategia de crecimiento económico de México basada en la liberalización financiera y comercial no ha funcionado adecuadamente para generar mayor crecimiento económico, mayor estabilidad en el sistema productivo nacional y mayor empleo. Por el contrario, la baja capacidad de recaudación fiscal, y por lo tanto de gasto público que tiene el Estado mexicano, no le han permitido seguir una política de fomento de las actividades productivas, por lo cual se ha promovido la apertura comercial y la apreciación cambiaria como los principales ejes de disciplina de los precios internos. Este esquema ha obligado a perpetuar la liberalización financiera a ultranza con el fin 
de obtener las divisas necesarias para financiar el déficit comercial y de cuenta corriente, ambos creados, asimismo, por este esquema de crecimiento económico orientado al sector externo y dependiente de Estados Unidos.

En consecuencia, lo que necesita con urgencia la economía mexicana es una reforma fiscal integral, es decir, una reforma fiscal progresiva basada primordialmente en el impuesto al ingreso y, en menor medida, en el impuesto al consumo. Las dos últimas administraciones, 2000-2012, han hecho énfasis en el impuesto al consumo y no en el impuesto al ingreso. Sin embargo, dado el nivel de pobreza de muchas familias mexicanas (40-50 millones de pobres, según la fuente), mayores impuestos sobre el consumo podrían revertir la expansión de la demanda agregada, y reducir así los ingresos fiscales.

Fundamentalmente, el gobierno mexicano debe apoyar a su industria nacional, tanto a las empresas nacionales que producen para le economía doméstica como a las que producen para el sector externo. Estos apoyos (subsidios, financiamiento, etc.) se deben otorgar sobre todo en estos momentos (2012), ya que el prolongado dinamismo de la economía de China ha empezado a traducirse en mayores salarios en este país, lo cual, de nueva cuenta, ha convertido atractiva a la economía mexicana como receptor de IED. Sin embargo, el mayor esfuerzo se debe hacer sobre las empresas nacionales que sean capaces de integrar las cadenas productivas. Desafortunadamente, el financiamiento a la industria nacional por parte de los bancos extranjeros en territorio nacional ha sido en extremo muy bajo, por lo que el gobierno mexicano, de tener mayores recurso fiscales derivados de una reforma fiscal integral, bien podría crear su propia versión del Banco Nacional de Desarrollo Económico y Social (Bndes) brasileño y apoyar así a la integración de la industria nacional.

Un mayor apoyo financiero por parte del gobierno hacia las empresas capaces de mitigar las importaciones (principalmente de maquila y de bienes finales) podría incrementar la productividad y modernización del aparato productivo nacional, con lo cual no solo se tendrían mayores niveles de producción de origen nacional y empleo, sino también se demandarían menores niveles de divisas y, consecuentemente, se tendría menor presión sobre el déficit comercial. Así, un menor déficit comercial y de cuenta corriente permitirían reducir la tasa de interés nacional (por la menor demanda de divisas), y ello podría reducir no solo el costo de financiamiento de la actividad productiva nacional, sino también contribuiría a un desahogado manejo de la cuenta de capitales y a la reducción del costo de la deuda pública interna, la cual, como analizamos en este trabajo, se ha incrementado considerablemente debido a las políticas de esterilización de capitales atraídos mediante altas tasas de interés.

Por último, dado el efecto negativo de la apreciación del tipo de cambio real sobre la producción nacional, las autoridades mexicanas deberían perseguir un 
tipo de cambio más competitivo, tal y como la ha hecho el gobierno argentino desde su crisis económica de 2001, lo cual le ha permitido crecer a tasas de $8 \%$ promedio anual en el periodo 2002-2011 (gráfica 1). Al respecto, cabe señalar que la principal vía de largo plazo para mantener un tipo de cambio competitivo es a través de un menor nivel de precios internos vis-à-vis los precios externos (Martínez, 2010). Por lo tanto, un mayor y eficaz apoyo del gobierno a las empresas nacionales podría incrementar el nivel de modernización y productividad de estas empresas, y llevar así a una reducción sistémica de precios internos, y con ello, a un tipo de cambio competitivo necesario para competir en la economía global.

\section{Referencias}

Ball, Christopher. P., y Javier Reyes, 2004, "Inflation targeting or fear of floating in disguise: the case of Mexico", International Journal of Finance and Economics, vol. 9, núm. 1.

Banco de México, s/f, disponible en <http://www.banxico.org.mx/estadisticas/index.html>.

Banco de México, 2007, "Mecanismo de opciones para acumular reservas internacionales", disponible en <http://www.banxico.gob.mx/portalesEspecializados/tiposCambio/didactico/ SubOpciones.html>.

Banco de México, 1999, Informe Anual, México, Banco de México.

Banco Mundial, World Development Indicators (varios años), disponible en <http://data.worldbank. org/data-catalog/world-development-indicators $>$.

Calva, José L. (coord.), 2012, Políticas macroeconómicas para el desarrollo sostenido, México, Juan Pablos/Consejo Nacional Universitario.

Calva, José L. (coord.), 2007, Macroeconomía del crecimiento sostenido. Agenda para el desarrollo, México, Dirección General de Publicaciones y Fomento Editorial-unam.

Gazol, Antonio, 2009, Bloques económicos, México, Facultad de Economía- unam.

Guillén Romo, Héctor, 2005, México frente a la mundialización neoliberal, México, Ediciones ERA.

Huerta, Arturo, 2011, Obstáculos al crecimiento: Peso fuerte y disciplina fiscal, México, Facultad de Economía-unam. 
Kregel, Jan, 1999, "Flujos de capital, banca mundial y crisis financiera después de Bretton Woods", Revista Comercio Exterior, vol. 49, núm. 1, Bancomext.

López, Teresa, 2012, "La intervención esterilizada del Banco de México en el mercado de cambios y la política de metal de inflación”, en José L. Calva (coord.), Políticas macroeconómicas para el desarrollo sostenido, Juan Pablos/Consejo Nacional Universitario.

Mántey, Guadalupe, 2010, Política monetaria con elevado traspaso del tipo de cambio, México, Plaza y Valdés.

Mántey, Guadalupe, 2009, "Intervención esterilizada en el mercado de cambios en un régimen de metas de inflación: la experiencia de México”, Investigación Económica, vol. LXVIII, núm. especial.

Mántey, Guadalupe, y Noemí Levy (coords.), 2007, Políticas macroeconómicas para países en desarrollo, México, Cámara de Diputados-LX Legislatura/FEs-Acatlán/DGAPA-UnAm/Miguel Ángel Porrúa.

Martínez-Hernández, Francisco, 2010, "An Alternative Theory of Real Exchange Rate Determination: Theory and Empirical Evidence for the Mexican Economy, 1970-2004", Investigación Económica, vol. LXIX, núm. 273, julio-septiembre, pp. 55-84.

Martínez Hernández, Francisco, 2005, "Determinantes del diferencial de tasas de interés México-Estados Unidos y del spread bancario en México, 1982-2004”, tesis de licenciatura, Facultad de Economía-UnAM.

Martínez Hernández, Francisco, 2003, "Efectos de la liberalización financiera sobre el crecimiento económico de México”, tesis de licenciatura, Facultad de Economía-unam.

Martínez Hernández, Francisco A., y Saúl Herrera Aguilar, 2006, "Debilidades y fortalezas de la industria petrolera en México, 1985-2005”, Economía Informa, núm. 340, mayo-junio.

Minian, Isaac, 2008, “Nuevas condicionantes internacionales de la industrialización”, en Eduardo Navarrete (coord.), Miscelánea global: tareas internacionales de México, CeIrH-unam (Prospectiva Global).

oecD, 2012, "Revenue Statistics", s/l, oecD Publishing.

Promexico, 2010, "Síntesis de la relación comercial México-Estados Unidos. Unidad de Inteligencia y Negocios”, disponible en <http:/www.promexico.gob.mx/work/models/ promexico/Resource/102/1/images/EstadosUnidos.pdf>. 
Pronafide (Programa Nacional de Financiamiento del Desarrollo), 1997, "Política sectorial. México”, disponible en <http://zedillo.presidencia.gob.mx/pub/programas/pronafide/ pronafide.html>.

Puyana, Alicia, y José Romero, 2009, De la crisis de la deuda al estancamiento económico, México, El Colegio de México.

Ros, Jaime, y Juan C. Moreno-Brid, 2009, Development and growth in the Mexican economy: A historical perspective, Oxford, Oxford University Press.

Secretaría de Economía, "Información estadística y arancelaria", disponible en <http://www .economia.gob.mx/comunidad-negocios/comercio-exterior/informacion-estadistica-y -arancelaria>.

Toporowski, Jan, 2005, “Limitaciones a la estabilización financiera por los bancos centrales”, en María Guadalupe Mántey Bastón, y Noemí Ornah Levy Orlik (coords.), Inflación, crédito y salarios: nuevos enfoques de política monetaria para mercados imperfectos, México, Cámara de Diputados/unam/Miguel Ángel Porrúa.

Recibido el 24 de enero de 2013. Aceptado el 21 de agosto de 2014. 